\title{
Rotation of sea/land breezes along the northeastern Adriatic coast
}

\author{
M. T. Prtenjak, Z. Pasarić, M. Orlić, and B. Grisogono \\ Department of Geophysics, Faculty of Science, University of Zagreb, Croatia \\ Received: 29 June 2007 - Revised: 25 April 2008 - Accepted: 29 April 2008 - Published: 18 June 2008
}

\begin{abstract}
The diurnal evolution of the sea/land breeze hodographs over the northeastern Adriatic coast has been examined for several episodes, each lasting a few days. A limited set of observations, as well as the results of a threedimensional nonhydrostatic mesoscale model are studied by applying a rotary-component method. This revealed a spatial distribution of the clockwise versus anti-clockwise rotation of the wind vectors for the sea/land breeze events. An application of the rotary-component method to the results of additional numerical sensitivity tests showed that the coastal topography height considerably influences both the shape of the wind hodographs and the sense of wind rotation. The method also displayed which areas are under a strong influence of the 24-h topographic forcing and which areas show a large wind consistency. A further analysis of the 24-h modeled wind hodographs at several selected stations has been performed, thus revealing the hodograph shapes and the reasons for them.
\end{abstract}

Keywords. Meteorology and atmospheric dynamics (Mesoscale meteorology; Ocean-atmosphere interactions) Oceanography: general (Numerical modeling)

\section{Introduction}

The sea/land breeze (SLB) is a coastal mesoscale feature commonly observed throughout the world. Up to now, many studies analyzed various aspects of the sea breeze (SB) system at different locations, resulting in a considerable amount of SLB-related knowledge (e.g. Simpson, 1994; Grisogono et al., 1998; Miller et al., 2003). These studies emphasized the SLB as a very complex phenomenon, encompassing the nonlinear interactions on several scales, from meso- $\beta$ to micro-scale. Likewise, the mean diurnal behavior of the

Correspondence to: M. T. Prtenjak

(telisman@irb.hr)
SLB along the northeastern Adriatic coast has also been a subject of several studies that used both the numerical (Nitis et al., 2005; Prtenjak et al., 2006) and the climatological methods (Orlić et al., 1988; Lukšić, 1989; Heimann, 2001; Pandžić and Likso, 2005; Prtenjak and Grisogono, 2007). Both approaches revealed some orographycally induced characteristics of the wind-field.

The northeastern Adriatic coast represents an example of a very indented shoreline with numerous islands and long and high coastal mountain ranges. This area covers the Istria peninsula, the mainland and the Kvarner Bay (Fig. 1). The Istria peninsula is surrounded by the sea on three sides. Mild and wavy relief shapes rise up towards the central part of the peninsula, to reach their highest point in the northeast, on the mountain massifs of Ćićarija and Učka. Učka mountain has quite a few valleys and crossways; it stretches over the total length of $20 \mathrm{~km}$, with the highest peak of $1396 \mathrm{~m}$. Pula-airport (1) is placed at the tip of peninsula near Pula, the largest town of Istria. At the foot of the mountain of Učka, the town of Opatija (2) is situated on the western side of the Rijeka Bay, being the oldest and one of the most popular tourist resorts at the coast. Rijeka (3) is the largest town in the whole area positioned between the coast and the mountains of Risnjak and Snežnik. The town of Malinska (4) is located on the eastern side of Rijeka Bay, on the island of Krk in the Kvarner Bay. Krk is the largest island in the Adriatic Sea with an area of approximately $410 \mathrm{~km}^{2}$ and the highest elevation of $569 \mathrm{~m}$ above sea level (m.s.l.). Kvarner Bay, itself, stretches from Opatija in the northwest to the island of Pag in the south and encompasses, besides Krk, the islands of Cres, Lošinj and Rab, which are in the immediate vicinity. The town of Senj (5) is the second largest coastal town in the selected region. It is situated between the sea and the slopes of V. Kapela and Velebit mountains $(\sim 1600 \mathrm{~m}$ above m.s.l.) near the Vratnik pass. Due to complex topography, many channels can be found in the Kvarner Bay; we will point out only a few: Great Gate, which separates the island

Published by Copernicus Publications on behalf of the European Geosciences Union. 
(a)
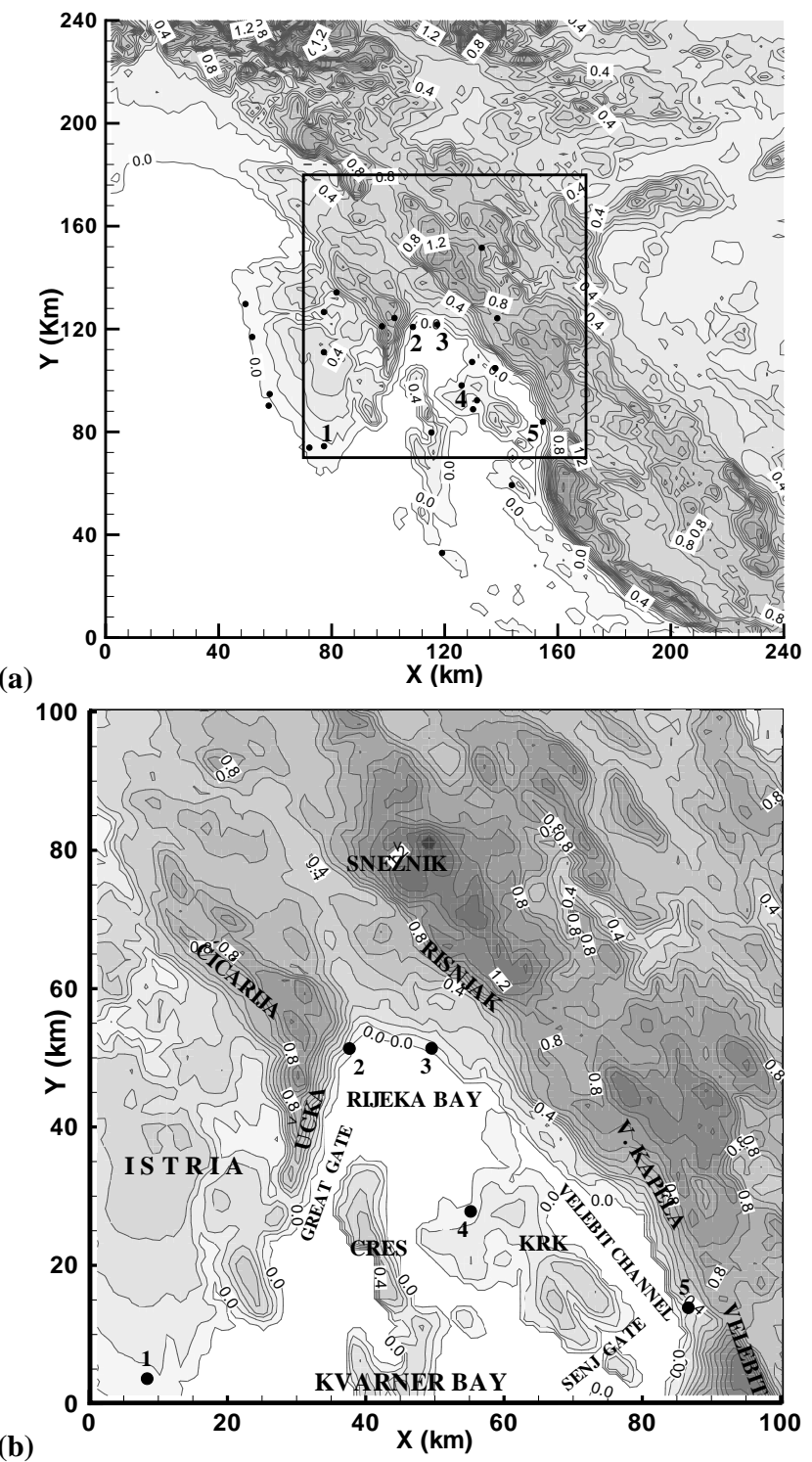

Fig. 1. Outer model domain (a) and inner model domain (b) also indicated by the square in (a). The measuring sites are $1=$ Pula-airport $\left(\phi=44^{\circ} 54^{\prime} \mathrm{N}, \lambda=13^{\circ} 55^{\prime} \mathrm{E}\right) ; 2=$ Opatija $\left(\phi=45^{\circ} 20^{\prime} \mathrm{N}\right.$, $\left.\lambda=14^{\circ} 19^{\prime} \mathrm{E}\right), 3=$ Rijeka $\left(\phi=45^{\circ} 20^{\prime} \mathrm{N}, \lambda=14^{\circ} 27^{\prime} \mathrm{E}\right), 4=$ Malinska $\left(\phi=45^{\circ} 7^{\prime} \mathrm{N}, \lambda=14^{\circ} 32^{\prime} \mathrm{E}\right)$ and $5=\operatorname{Senj}\left(\phi=45^{\circ} 0^{\prime} \mathrm{N}, \lambda=14^{\circ} 54^{\prime} \mathrm{E}\right)$. Additional black dots in (a) represent other meteorological and climatological stations located in the area. Topography contours are plotted every $100 \mathrm{~m}$ between at $0 \mathrm{~m}$ and $1700 \mathrm{~m}$. The contours of $0 \mathrm{~m}, 400 \mathrm{~m}, 800 \mathrm{~m}$ and $1200 \mathrm{~m}$ are labeled as $0.0,0.4,0.8,1.2$, respectively. See text for geographical details.

of Cres from Istria; Velebit Channel, which lies between the island of Krk and the mainland; and Senj Gate south from the island of Krk.

A numerical three-dimensional SLB simulation (18-20 June 2000) for the northeastern Adriatic coast (Prtenjak et al., 2006) revealed the formation of several small-scale phe-

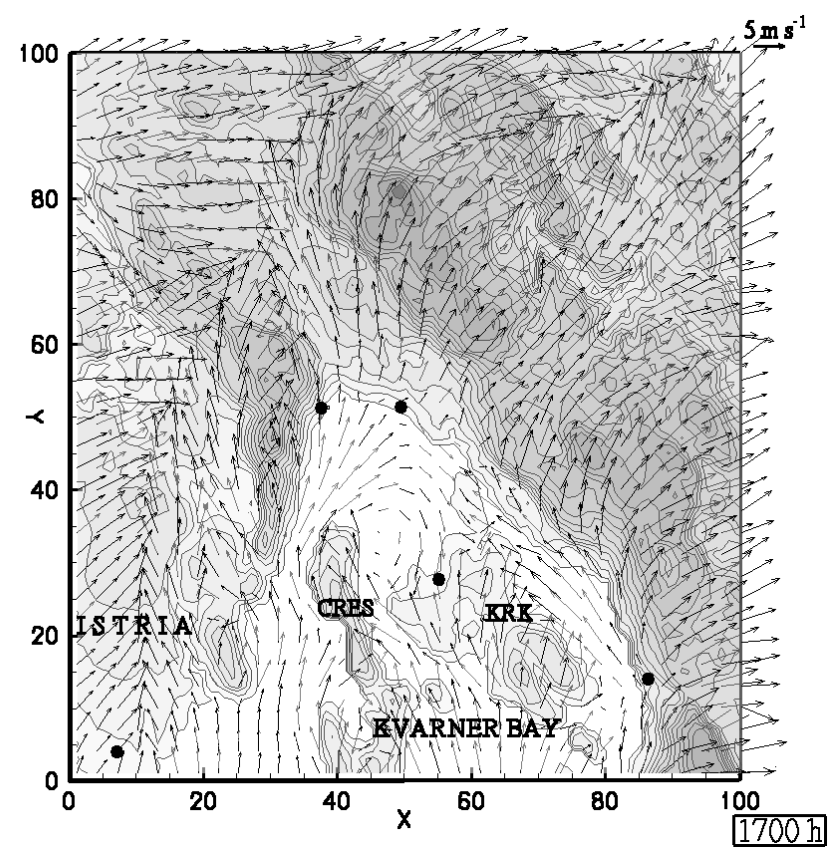

Fig. 2. Model predicted surface wind field at $10 \mathrm{~m}$ at 17:00 local standard time on 20 June 2000 above Istria and Kvarner Bay from Prtenjak et al. (2006). The wind vectors are given at a horizontal resolution of $3 \mathrm{~km}$, with a reference vector drawn near the upper right-hand corner. Black dots correspond to the automatic meteorological stations (numbers 1-5 in Fig. 1).

nomena e.g. the mesoscale eddies inside the Rijeka Bay and convergence zones above Istria and the island of Krk. The surface wind field is significantly canalized through Velebit Channel and also between Istria and the island of Cres, through Great Gate (Fig. 2). Mesoscale eddies evolved inside the Rijeka Bay during $24 \mathrm{~h}$ as a result of topographic forcing. During the day, both the anabatic flow and the well developed SB that are caused by the coastal geometry and the terrain height resulted in the afternoon anticyclonic vortex inside the shallow stable marine boundary layer (Fig. 2). The night-time cyclonic eddy developed due to katabatic flow from the surrounding mountains (not shown). Above Istria, the daytime merged SBs formed the convergence zone that moved eastward. Over the island of Krk, there is another orographically-induced convergence zone (Fig. 2).

As it is well known, the usual sense of wind rotation on the Northern Hemisphere is clockwise (CW) due to the Coriolis force (Haurwitz, 1947). Still, the anti-clockwise (ACW) wind rotation was reported for many stations around the world (e.g. Alpert et al., 1984; Kusuda and Abe, 1989; Steyn and Kallos, 1992; Simpson, 1996). According to Kusuda and Alpert (1983), the ACW rotation is possible only in the presence of a complex topography near the shore. The dynamical analysis made by Kusuda and Alpert (1983) and Steyn and Kallos (1992) showed that the wind rotation is controlled by the balance of forces in the horizontal momentum equation. 
Along the very complex northern Croatian coast, the investigation of the observed winds for Malinska and Senj also indicated the ACW rotation (e.g. Orlić et al., 1988; Prtenjak, 2003; Prtenjak and Grisogono, 2007). Orlić et al. (1988) presumed that the ACW pattern of diurnal breezes at Senj station is connected with the alongshore pressure gradient. In a recent study by Prtenjak and Grisogono (2007) the observed wind hodographs have been examined for ten locations along the northeastern Adriatic coast: two stations with $\mathrm{ACW}$ wind rotation were detected out of ten observed hodographs, i.e. with a relative frequency of 0.2. Alpert et al. (1984) have considered the relative frequency of ACW rotation as a function of latitude on the basis of numerous observations and have compared it to the results of a simple analytical theory. From the complex shapes of the observed hodographs the first-order ellipses have been extracted by applying the harmonic analysis. Best agreement with the data has been obtained when performing analytical modeling under the following assumptions: (1) amplitudes of thermal forces in both horizontal directions are equal, (2) different phase shifts between the thermal forces in the full region $<-180^{\circ}, 180^{\circ}>$ follow constant probability distribution, and (3) friction is equal to the angular speed of the Earth's rotation. The results imply that the relative frequency of ACW rotation in temperate latitudes typically falls between 0.3 and 0.4 . Of course, particular values may be found outside these limits, due to the specifics of the coastline shape, topographic features and friction processes, but the basic control of the Coriolis force apparently favors the above-mentioned range.

The present study investigates the spatial distribution of locations with $\mathrm{CW}$ versus $\mathrm{ACW}$ behavior of the local wind vectors. Such spatial distribution will reveal parts of the coast that are under significant topographic influence, thus showing other locations with prevailing $\mathrm{ACW}$ rotation that are still unknown. For this purpose, the rotary-component method (Gonella, 1972) is applied to the simulated surface wind fields that are obtained by the three-dimensional nonhydrostatic numerical model for several real SLB cases (as in Nitis et al., 2005, and Prtenjak et al., 2006). The case that occurred on 18-20 June 2000, presented in Prtenjak et al. (2006), is examined in more detail. To obtain some confidence in the model performance, the same method is applied to winds that were observed at five meteorological stations. In order to analyze the cause of the wind rotation in more detail, the rotary-component method is also applied to the results of sensitivity tests, where the terrain variations are removed as in Prtenjak et al. (2006). Finally, an additional analysis of the modeled wind hodographs at several selected positions has been performed in order to examine the smallscale local effects.

\section{Methods and data}

\subsection{Rotary-component method}

Rotary analysis of vector time series (e.g. of the horizontal wind, $\boldsymbol{V}=u_{x} \boldsymbol{i}+u_{y} \boldsymbol{j}$ ) aims to separate the vector at a specific Fourier frequency into two circular components, one rotating $\mathrm{CW}$ and the other one rotating $\mathrm{ACW}$. The method is especially suitable in situations when, due to the Earth's rotation, asymmetric behavior at certain frequencies could be expected. Let $\left(u_{x \omega}, u_{y \omega}\right)=\left(A_{x \omega}, A_{y \omega}\right) e^{2 \pi i \omega t}$ be the Fourier component of a real, vector time series at a particular frequency $\omega$. Then, omitting $\omega$ in the indices, we have (Gonella, 1972):

$$
\begin{aligned}
u_{x}+i \cdot u_{y} & =u_{+} e^{2 \pi i \omega t}+u_{-} e^{-2 \pi i \omega t}= \\
e^{i \theta}\left[\left(\left|u_{+}\right|\right.\right. & \left.+\left|u_{-}\right|\right) \cos (2 \pi \omega t+\tilde{\theta}) \\
& \left.+i\left(\left|u_{+}\right|-\left|u_{-}\right|\right) \sin (2 \pi \omega t+\tilde{\theta})\right],
\end{aligned}
$$

where $u_{+}=A_{x}+i \cdot A_{y}, u_{-}=A_{x}-i \cdot A_{y}, \theta=1 / 2 \operatorname{Arg}\left(u_{+} \cdot u_{-}\right)$, $\tilde{\theta}=1 / 2 \operatorname{Arg}\left(u_{+} \cdot \bar{u}_{-}\right), i=\sqrt{-1}$, and the overline denotes the complex conjugate. The superposition of two circular motions (CW with radius $\left|u_{+}\right|, \mathrm{ACW}$ with radius $\left|u_{-}\right|$) results in the overall elliptical motion. The ellipse axes are $\left|u_{+}\right|+\left|u_{-}\right|$ and ||$u_{+}|-| u_{-}||$, while the orientation of major axis is given by $\theta$. If $\left|u_{+}\right|<\left|u_{-}\right|\left(\left|u_{+}\right|>\left|u_{-}\right|\right)$, the ellipse is traced in the $\mathrm{CW}(\mathrm{ACW})$ direction, while $\left|u_{+}\right|=\left|u_{-}\right|$results in the purely rectilinear back and forth motion. The variance (or the kinetic energy) at the considered frequency is proportional to $\left|u_{+}\right|^{2}+\left|u_{-}\right|^{2}$. Thus, the overall CW (ACW) motion implies that the $\mathrm{CW}(\mathrm{ACW})$ component is more energetic than the $\mathrm{ACW}(\mathrm{CW})$ one.

We are interested primarily in the SLB signal which should occur around the 24-h period and usually lasts only a few days. Thus, the analysis described above is applied to the 24$\mathrm{h}$ harmonics that are extracted from both wind components separately by a least-squares fitting. Recalling that the variance of vector time series is simply the sum of component variances, the goodness of fit is determined as the quotient of the variance described by the fit and the total variance. In the case of a scalar time series this quotient equals the correlation coefficient squared, so we retain the same name here.

The shortness of the analyzed interval is overcome by using a set of SLB episodes. The time series related to several SLB episodes for a fixed geographic location may be considered as independent realizations of a stochastic process. For this case Gonella (1972) developed several useful quantities describing the average behavior of wind ellipses $(<\cdot>$ denotes the averaging over episodes): The positive, $S_{+}=\left\langle\left|u_{+}\right|^{2}\right\rangle$, and negative, $S_{-}=\left\langle\left|u_{-}\right|^{2}\right\rangle$, rotary spectra give the average variance contained in the $\mathrm{CW}$ and $\mathrm{ACW}$ rotary component, respectively. The coefficient of stability, $\left|\left\langle u_{+} u_{-}\right\rangle\right| /\left(S_{+} S_{-}\right)^{1 / 2}$, measures the "coherence" between 
Table 1. Simulations performed in the present study.

\begin{tabular}{cccc}
\hline Case & Date interval & Topography height & Islands \\
\hline A_T1 & 18-20 June 2000 & Real & Yes \\
A_T2 & 18-20 June 2000 & Real & No \\
A_T3 & 18-20 June 2000 & Terminated at 10 $\mathrm{m}$ & Yes \\
B_T1 & 25-27 June 1999 & Real & Yes \\
C_T1 & 6-8 September 1999 & Real & Yes \\
D_T1 & 25-27 June 2001 & Real & Yes \\
\hline
\end{tabular}

the ellipses. It equals one if the ellipses from all realizations are equally oriented and have one and the same eccentricity. Opposite, a zero value means that there is no correspondence at all. Mean orientation is given by $1 / 2 \operatorname{Arg}\left(\left\langle u_{+} u_{-}\right\rangle\right)$. The rotary coefficient, $\left(S_{-}-S_{+}\right) /\left(S_{+}+S_{-}\right)$, measures the degree of polarization, while its sign indicates (on average) the direction in which the ellipses are traced.

\subsection{Model overview and application}

A description of the three-dimensional nonhydrostatic mesoscale meteorological model MEMO6 that is used in this work may be found in Moussiopoulos (1994), Kunz and Moussiopoulos (1995), Klaić et al. (2002), Nitis et al. (2005), Prtenjak et al. (2006). The model is widely utilized for simulations of coastal flows (e.g. Sandvik, 1998; Soriano et al., 2001; Caballero and Lavagnini, 2002) where it showed an ability to successfully reproduce various mesoscale phenomena (e.g. Klaić et al., 2002; Prtenjak et al., 2006). In the present work, the model domain has two coupled horizontal grids; the inner grid $\left(100 \times 100 \mathrm{~km}^{2}\right.$ with $\Delta x=\Delta y=1 \mathrm{~km})$ is nested into the outer one $\left(240 \times 240 \mathrm{~km}^{2}\right.$ with $\Delta x=\Delta y=2 \mathrm{~km}$ ), Fig. 1 . The chosen resolution of $1 \mathrm{~km}$ is fine enough to resolve a phenomenon such as SLB that develops on the scale of, for example, several tens of kilometers. It should mostly prevent the overlapping effect between the TKE parametization and the resolved boundary layer (e.g. Wyngaard, 2004). For higher resolution than $1 \mathrm{~km}$, it will become necessary to use a 3-D turbulence. The model top is at $8000 \mathrm{~m}$ in both domains. The vertical resolution that is applied here ranges from $20 \mathrm{~m}$ near the surface to $1100 \mathrm{~m}$ toward the top. The initial and the boundary conditions (wind and temperature) are prescribed from the ALADIN/LACE model (e.g. Bubnova et al., 1995; Ivatek-Šahdan and Tudor, 2004) at $12 \mathrm{~km}$ horizontal resolution. The boundary conditions are updated every $12 \mathrm{~h}$ during numerical simulations. The land-use data are taken from the Global Land Cover Database and the topography is derived from the GTOPO30 database. Seven land-use types are employed.

The model uses a one-way nesting technique in order to account for all relevant orographic influences on the flow field. The temperature and moisture at the surface are re- produced by the energy- and water-budget equations (Sandvik, 1998). The surface temperature is calculated by a heat balance equation using a Newton iteration technique. The soil humidity is parameterized according to Deardorff (1978), and the prognostic equation for the specific humidity is solved without condensation processes. The sea surface temperature is constant throughout the simulation. The turbulent diffusion terms, related to calculating the TKE, are treated via a simplified higher-order closure scheme (Moussiopoulos 1994; Kunz and Moussiopoulos, 1995). The mixing length is given by Blackadar (1962).

\subsection{Data}

Here, a well-studied interval (the A_T1 case), as in Prtenjak et al. (2006), covering 18-20 June 2000 is further analyzed, as are three additional multi-day episodes: 25-27 June 1999 as the B_T1 $_{-}$case, 6-8 September 1999 as the $\mathrm{C}_{-} \mathrm{T} 1$ case and 25-27 June 2001 as the D_T1 case (see Table 1). According to the surface and the upper-level analyzed meteorological fields over Europe, throughout the intervals examined only a weak synoptic forcing is present over the northeastern Adriatic coast. Under such sunny and dry weather conditions (a weak diurnal pressure variation, cloudiness $<4 / 10$ and landsea temperature difference greater than $3^{\circ} \mathrm{C}$ ), a complex SLB development is inevitable. The chosen periods are characterized by relatively low cloudiness, with absolutely no precipitation, and, therefore, only a minor influence of the moist processes on the mesoscale wind field is expected in our cases. To assess the effects that topography exerts on the mesoscale wind field, besides the A_T1 simulation two sensitivity tests are also performed. According to the preceding numerical results (Prtenjak et al., 2006), as described briefly in the Introduction, a natural choice was to examine the influence of islands and topography height on the wind field in more detail. Therefore, in the first test (A_T2) the islands are replaced by sea surface, while in the second test (A_T3) all terrain is replaced by a more homogeneous terrain with heights terminated at $10 \mathrm{~m}$.

\section{Results}

\subsection{Overall comparison}

Meteorological stations along the northern Croatian coast (Fig. 1) with hourly measurements of the near-surface wind are Pula-airport, Opatija, Rijeka, Malinska and Senj. These sites, as described in the Introduction, are representative of various geographical features. A number of additional stations, both meteorological and climatological (unsigned dots in Fig. 1), are utilized for overall comparison between the data and the A_T1 results for 19 June 2000 (Fig. 3). A good agreement is found between modeled and measured winds at $14: 00 \mathrm{~h}\left(r_{\text {speed }}=0.77\right.$ and $\left.r_{\mathrm{dir}}=0.76\right)$ and slightly less so at $21: 00 \mathrm{~h}\left(r_{\text {speed }}=0.73\right.$ and $\left.r_{\mathrm{dir}}=0.68\right)$. Slight overestimation (at 

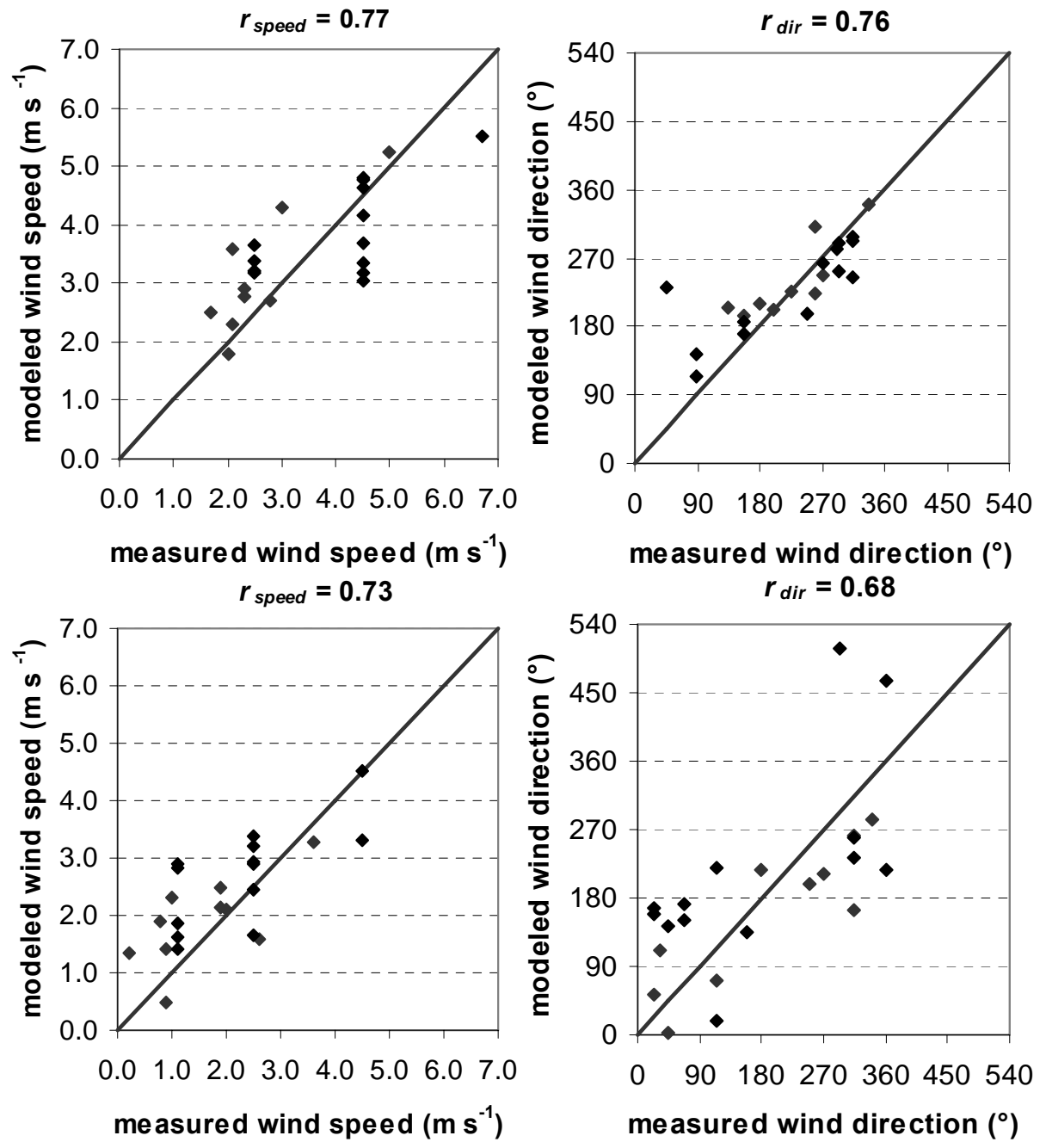

Fig. 3. The modeled versus measured hourly averaged surface wind speed (left) and wind direction (right) for 19 June 2000 at 14:00 h (top) and at 21:00 h (bottom). Black diamonds mark the comparison between the model and the data obtained from both automatic meteorological and climatological stations (signed and unsigned dots in Fig. 1). The corresponding correlation coefficient is also given at each panel. In order to show exact discrepancies between the measured and modeled directions, wind directions spanning a range of $0-90^{\circ}$ are sometimes enlarged by $360^{\circ}$.

21:00 $\mathrm{h}$ in Fig. 3) is seen for the wind speeds lower than $2 \mathrm{~m} \mathrm{~s}^{-1}$ that are generally difficult to model (e.g. Mahrt and Vickers, 2006; Mahrt, 2007). The reasons may be, for example, the constant sea surface temperature in the model, the smoothing of the model terrain, and the parameterization of turbulent fluxes during the night in the stable boundary layer, according to the Monin-Obukhov theory (e.g. Grisogono et al., 2007).

\subsection{Rotary components}

\subsubsection{8-20 June 2000}

The method of rotary components is applied first to the hourly wind measurements collected between noon of 18
June 2000 and midnight of 20 June 2000 at the considered sites (Fig. 4). The results for Pula-airport, Rijeka and Malinska show that the surface wind is well described by fitting the 24-h harmonic, the correlation coefficient squared ranging between 0.5 (Pula-airport) and 0.69 (Rijeka). This indicates that the diurnal wind regime is the dominating feature at these stations. The wind in Opatija is still reasonably well described by the diurnal harmonic, although the correlation coefficient squared of 0.39 suggests the importance of processes at shorter time scales. In Senj, a portion of the diurnal harmonic drops to 0.16 , which means that during the interval examined, the SLB phenomenon is overwhelmed by the additional local and nonlinear processes. The reason can be the daily varying influence of air flow canalizing inside 

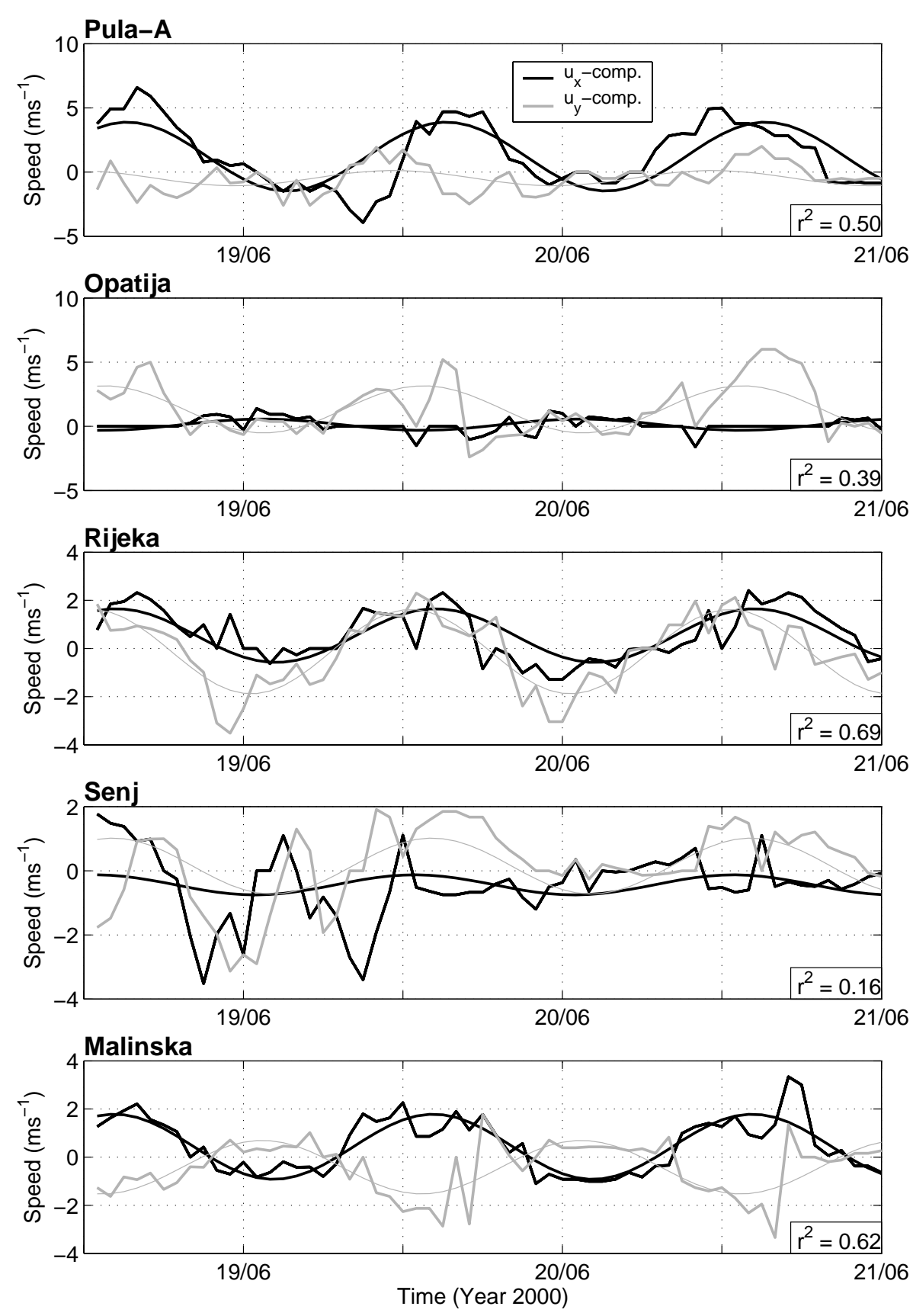

Fig. 4. Measured hourly values of the near-surface wind and the corresponding 24-h harmonics fitted ( $u_{x}-$ east-west wind component; black, $u_{y}$ - north-south wind component; grey) at selected stations from noon, 18 June 2000, until midnight, 20 June 2000 . The correlation coefficient squared is indicated in the lower right corner.

the Velebit Channel (Fig. 2) and the development of a bora wind. The SLB climatological study (Prtenjak and Grisogono, 2007) for Senj revealed somewhat unusual characteristics. The SB there is the shortest and the weakest of all stations along the northeastern Adriatic coast, achieving the maximal strength at 11:00 h local time. Moreover, the SB at Senj is twice weaker than the offshore flow, which itself is not a pure land breeze, since other mesoscale phenomena, such as bora, can contribute to the strengthening of the offshore flow.

Figure 5 shows the ellipses corresponding to the 24-h harmonics for the analyzed interval for both the measurements (black) and the corresponding grid points from the model (A_T1 case, grey). Thus, at Pula-airport and Rijeka pronounced CW rotation exist, while Malinska and Senj are characterized by a ACW rotation. Opatija is described by the 

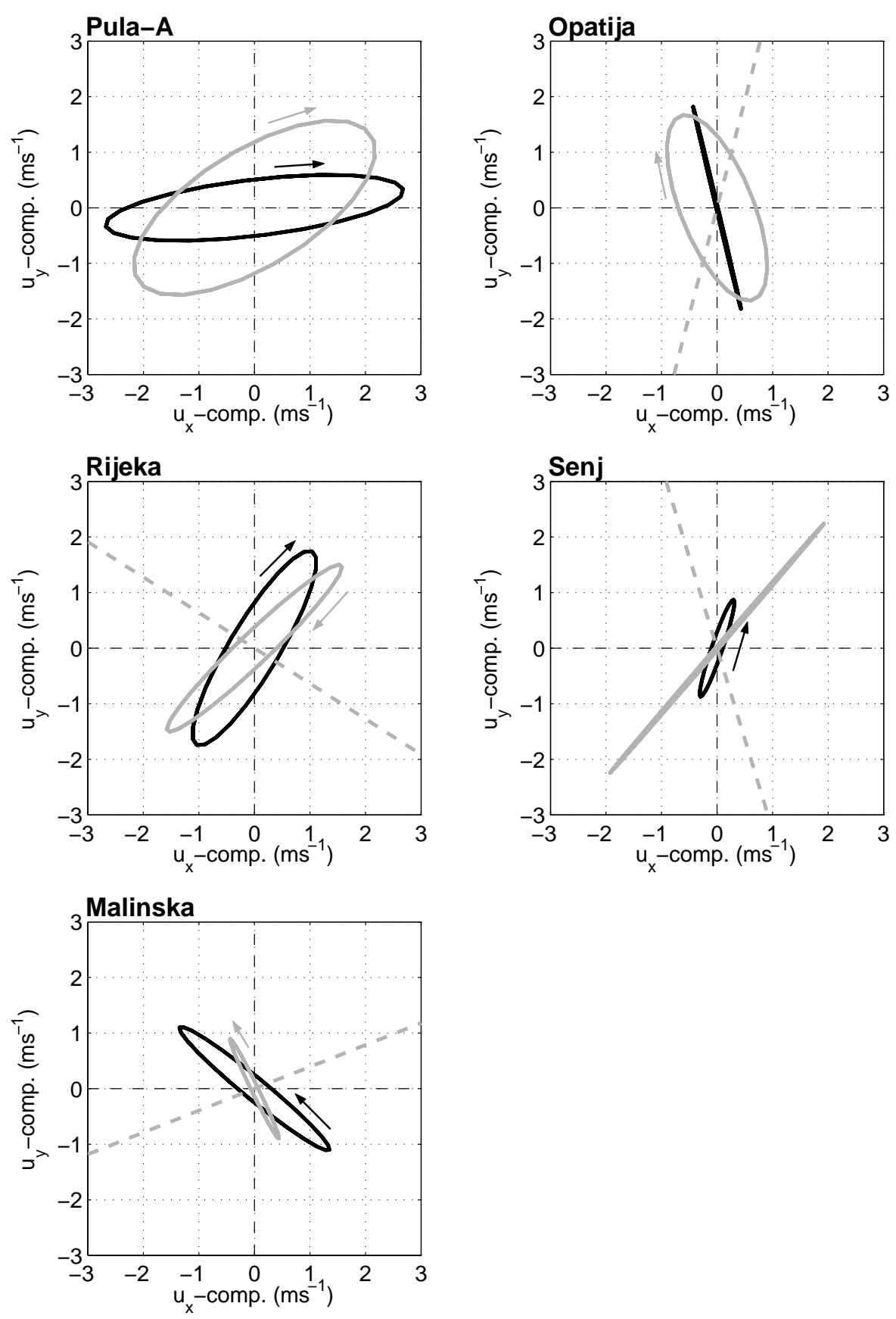

Fig. 5. The 24-h wind ellipses for the selected stations and the corresponding grid points from the inner domain during $18-20$ June 2000 (A_T1 case): measurements (black) and model (grey). The arrow indicates sense of rotation of the wind vectors (omitted in case of highly polarized ellipses, e.g. for Opatija and Senj). The dashed line represents the orientation of the local coastline. The exception is Pula-airport, which is situated at the tip of Istria peninsula with the nearest coastline being $10 \mathrm{~km}$ away.

highly polarized ellipse. In general, comparison between the measured and modeled diurnal 24-h harmonics - concerning the length of the ellipse axes - shows reasonable agreement. The correlation coefficient squared for the modeled 24-h harmonic is generally higher than for the measured one, ranging from 0.67 at Pula-airport to 0.86 at Opatija. Only in Ma- linska is the model correlation coefficient squared somewhat lower $\left(r^{2}=0.33\right)$, opposite to the measured 24-h harmonic. Presumably, the model is not able to fully capture all the measured wind variations that are caused by the local effects (e.g. building effects especially around the measurement site and the coastline irregularities - since Malinska station is placed 

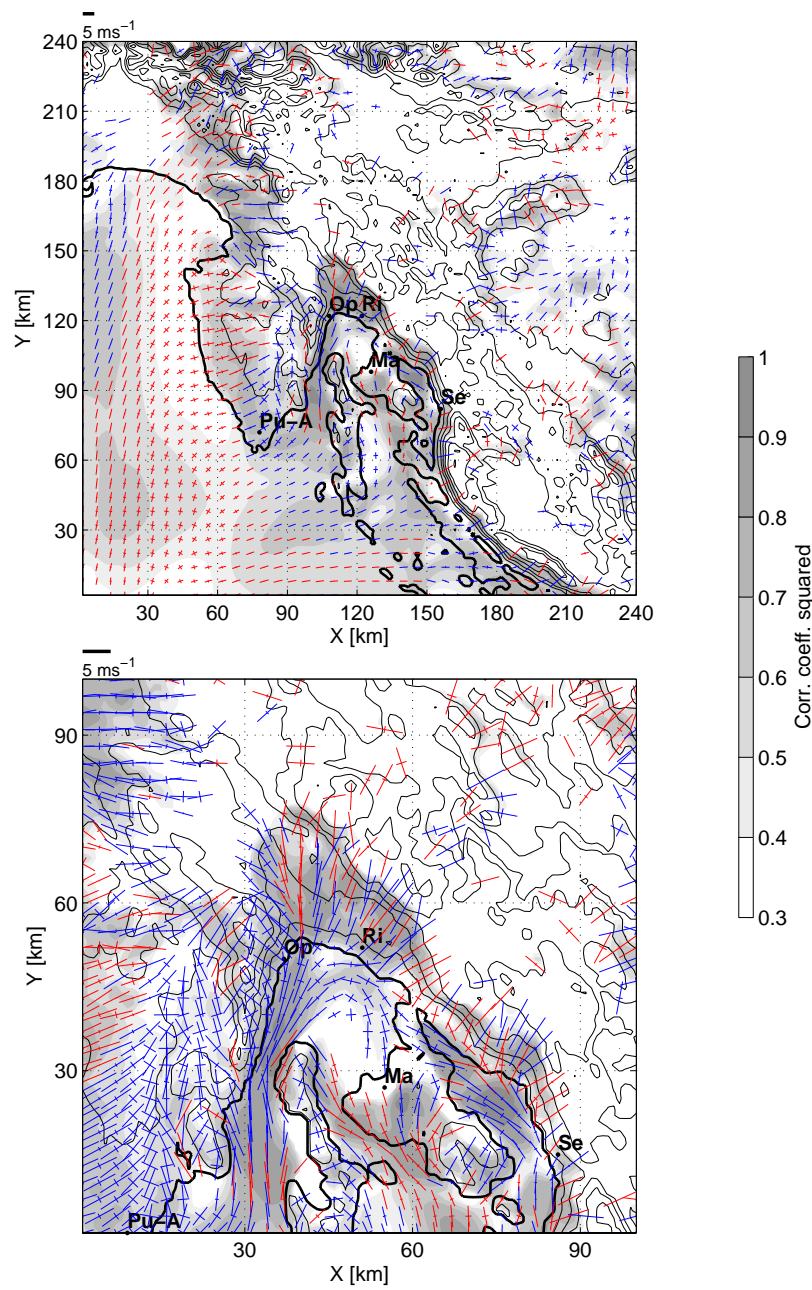

Fig. 6. Axes of ellipses corresponding to the fitted diurnal harmonics of the surface wind for the A_T1 case; outer domain (top), inner domain (bottom). The correlation coefficient squared (indicating the percentage of variance explained by the harmonic) is depicted in a gray scale. While blue ellipses exhibit the clockwise rotation, the red ones show the anti-clockwise rotation.

in a small bay). Some of the observed variability may also have to do with other things, such as ill selected observation locations and poorly located sensors.

Next, the rotary components of the surface wind are calculated for the A_T1 case simulation at every grid point, thus revealing the spatial distribution of the wind rotation. Figure 6 depicts the 24-h wind ellipses and their sense of rotation for grid points at which the total variance explained by the 24-h harmonic is not less than 0.3. At first glance, we can observe several $\mathrm{CW}$ and $\mathrm{ACW}$ rotation regions. The coastal areas with the pronounced ACW rotation are the NW part of the Istria peninsula, the area between Ćićarija and Risnjak mountains, the larger western part of the island of Krk, as well as the western part of the island of Cres and the mainland near Velebit Channel (Fig. 6, top). Other parts of the

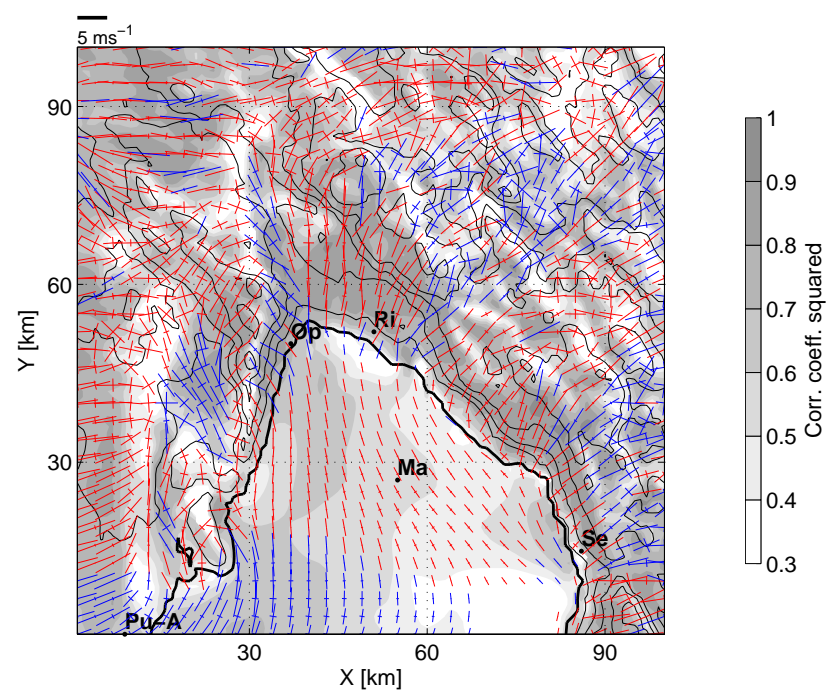

Fig. 7. Same as in Fig. 6 (bottom) but for the simulation without islands (A_T2).

northern Croatian coast are characterized by the $\mathrm{CW}$ rotation. Interesting enough, these results agree with the findings of Alpert et al. (1984), who found that in temperate latitudes one-third of an area may typically be expected to have hodographs characterized by ACW rotation.

The sensitivity test A_T2 shows topographical and geographical effects on the spatial distribution of both the CW and ACW rotation of the 24-h harmonic (Fig. 7). In general, the correlation coefficient squared is higher at the majority of the grid points (especially in the hinterland) as compared to the A_T1 case. This suggests that the wind blows more regularly during $24 \mathrm{~h}$ between land and sea, since the sea surface is more homogeneous in the A_T2 case. According to Prtenjak et al. (2006), in this test some dynamical forms, such as mesoscale eddies in the Rijeka Bay, disappeared. The absence of islands prevented a modification of the SB from the Kvarner Bay. This resulted in a stronger daytime easterly onshore flow as compared to the A_T1 case. It retarded more efficiently a daytime eastward movement of both the westerly $\mathrm{SB}$ and the convergence zone along the peninsula. Therefore, due to overall changes in the wind field, the Istria peninsula and Risnjak, as well as a large portion of the Kvarner Bay represent the areas with significant prevailing ACW rotation. Pula-airport is in the area of CW rotation, while the ACW rotary motion around Senj still exists. Opatija and Rijeka are in the area where ACW and CW rotations interchange. In the case of flat topography (A_T3), the very marked CW rotation exists everywhere without exception (not shown). The coastline orientation itself has a smaller impact on the sense of the wind rotation, in comparison to the terrain that changes the wind veering considerably. Still, there is a correlation between the effects of the terrain and the coastline orientation, since the terrain follows the coast. This result confirms 

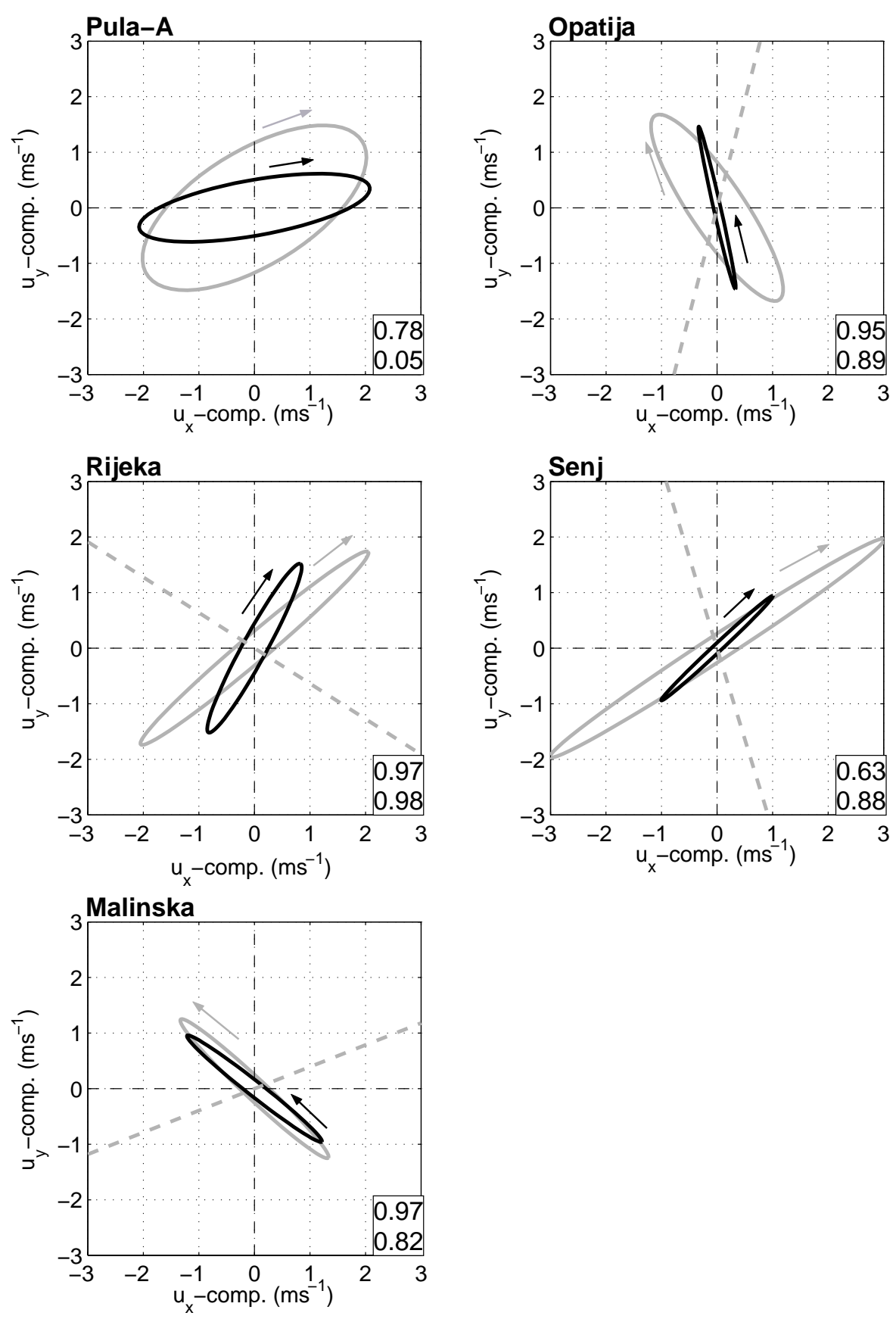

Fig. 8. The averaged ellipses for four different multi-day intervals for the selected stations and corresponding grid points in the inner domain: measurements (black) and model (grey). The stability parameters are depicted in the lower right corner: measurements (above) and model (below). The arrow indicates the sense of rotation of wind vectors and the dashed line the orientation of the local coastline. The exception is Pula-airport, which is situated at the tip of Istria peninsula with the nearest coastline being $10 \mathrm{~km}$ away.

that some coastal parts are highly affected by the height of the coastal terrain and its orientation, since in the A_T3 case both the coastal geometry and the synoptic conditions had been kept the same as in the A_T1 case.

\subsubsection{Average spatial distribution}

The SLB pattern studied here lasts continuously for only a few days. The shortness of the analyzed interval is overcome by employing the numerical model on the set of SLB episodes. Therefore, besides the A_T1 case, the same 


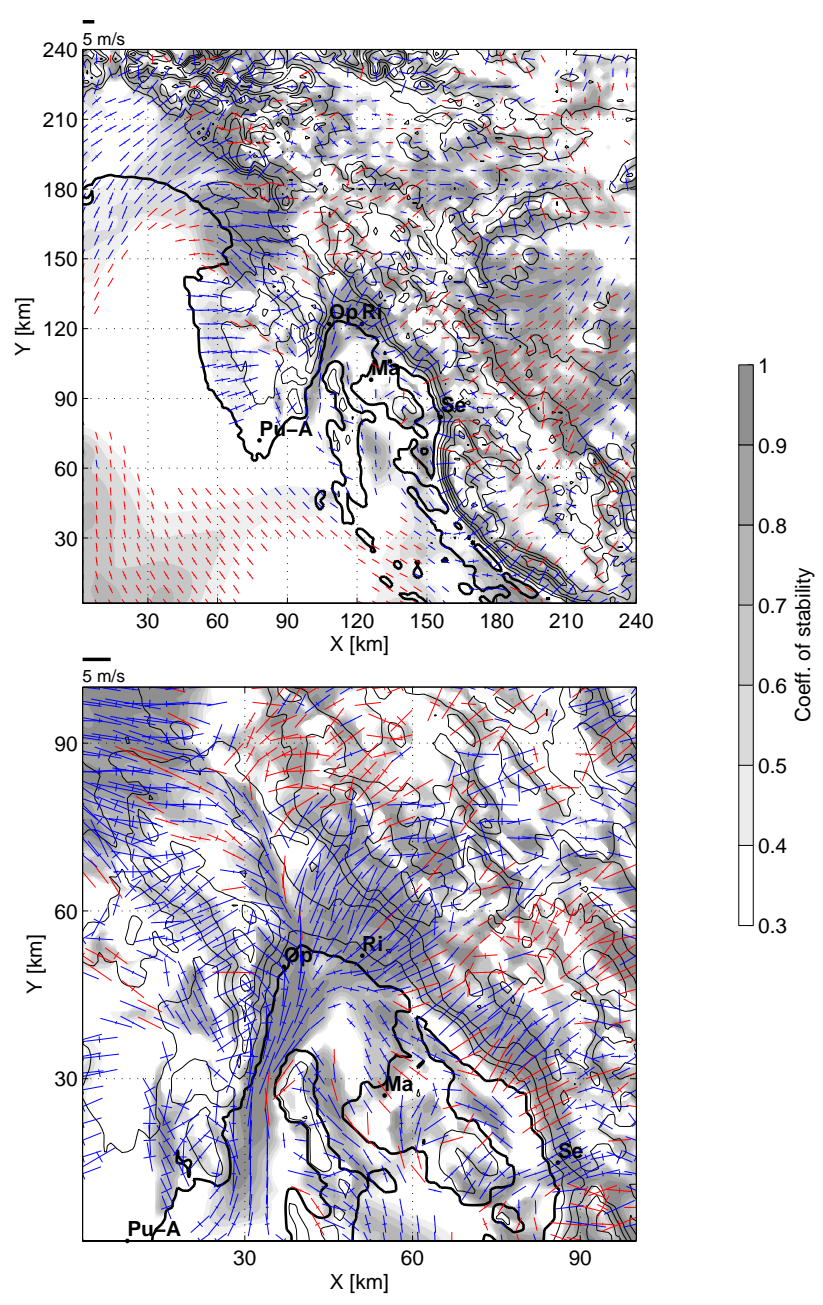

Fig. 9. The axes of averaged ellipses for four modeled multi-day intervals, outer domain (top), inner domain (bottom). The stability coefficient (indicating the coherence among eccentricities and tilts of main axes) is depicted in gray scale. The $\mathrm{CW}$ rotation is displayed in blue, the ACW rotation in red.

approach has been applied to the model outputs for B_T1, C_T1 and D_T1 cases. As a final result, average ellipses of the 24-h harmonics were calculated for both measurements and model outputs and the average distribution of $\mathrm{CW}$ and ACW regions for four SLB cases is provided.

In general, the averaged measured ellipses are reasonably well reproduced by the averaged modeled ones (Fig. 8). The only discrepancy is observed at Opatija in the sense of rotation. While the model shows the $\mathrm{CW}$ rotation, the measured 24-h harmonic there displays the highly polarized ellipse with ACW rotation. Note, however, that a highly polarized ellipse implies that the sense of rotation is sensitive to small errors. The averaged measured and modeled ellipses are also similar to those in the A_T1 case (compare Figs. 5 and 8).
The coefficient of stability for the measurements is large for all stations, ranging from 0.63 (Senj) to 0.97 (Malinska and Rijeka) and showing considerable wind consistence for a 24-h period. For simulated ellipses, the coefficients of stability depict very similar characteristics. The exception is Pula-airport with the coefficient of stability of only 0.05 for the modeled ellipses. Such a low value is due to the peculiar station location, which is significantly influenced by the convergence zone above Istria and its movement, which is generally eastward. In the four simulated cases, this site always displays $\mathrm{CW}$ rotation, the ratio between major and minor axis is similar, but the slope of the major axis varies significantly (not shown), resulting eventually in the low coefficient of stability.

In Fig. 9, a wind consistency represented by the coefficient of stability is depicted as grey filled regions. The sea side slopes and channels (e.g. Great Gate and Senj Gate), as well as the western part of Istria peninsula show high wind consistency (the coefficient of stability $>0.5$ ). In contrast, a part of Istria and some parts of the island of Krk, which are under significant influence of the convergence zones (Prtenjak et al., 2006), have a substantial variability due to the zones' daytime positions. The SW part of the open sea (top panel) is characterized by both the low variability of the wind and the ACW rotation. Averaged spatial distribution of the 24-h averaged wind ellipses, which is seen to be similar to the A_T1 case alone, is characterized by several $\mathrm{ACW}$ areas: along the slopes of V. Kapela and Velebit mountain, between Ćićarija and Risnjak, in the center of the island of Krk, around Malinska, and in some NW parts of the island of Cres. Also, as in the A_T1 case, a large ACW area exists in the hinterland. Around Senj, the highly polarized ellipses are found, with the zone of ACW rotation being flanked by the smaller area of $\mathrm{CW}$ rotation. Opatija and Rijeka are in the $\mathrm{CW}$ region. A large part of Istria, including Pula-airport is characterized by the $\mathrm{CW}$ rotation (see also Fig. 8).

\subsection{Model hodographs on 19 June 2000}

In the previous section, the overall spatial distribution of the wind rotation is obtained, for the first time, by the rotarycomponent method. The areas with the prevailing ACW or $\mathrm{CW}$ rotation are detected, which was not possible from the measurements alone. Still, a finer diurnal SLB analysis can only be made by examining the whole $24-\mathrm{h}$ wind regimes. Hence, particular attention is paid to the comparison between the hodographs obtained for the A_T1 case on 19 June 2000, related to Pula-airport, Opatija, Rijeka and Malinska. The aim is to explain the basic local effects influencing the local wind dynamics at the considered stations. Senj is excluded here due to its low correlation coefficient squared related to the 24-h harmonic.

At Pula-airport (Fig. 10a), both measured and modeled wind vectors, which are under the convergence zone's influence, rotate in the $\mathrm{CW}$ direction. Measurements show 

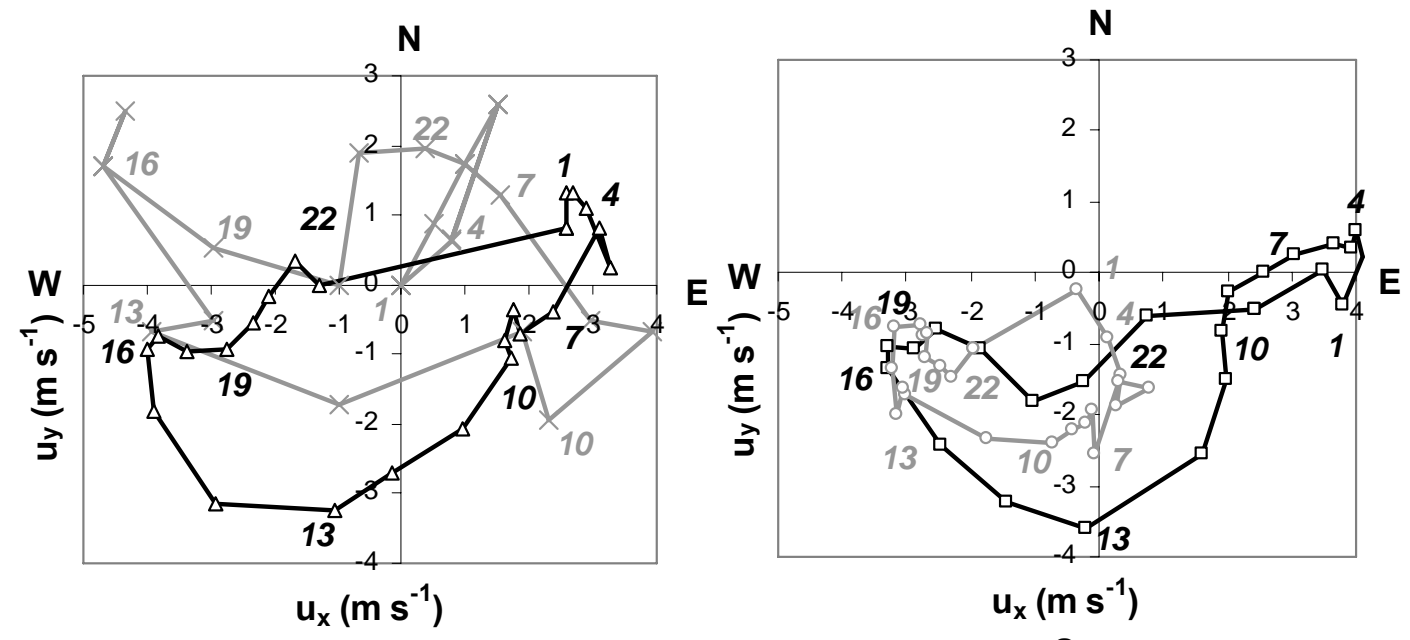

$\mathrm{S}$

(a)

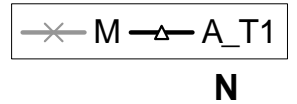

$\mathbf{S}$

$\mathbf{N}$
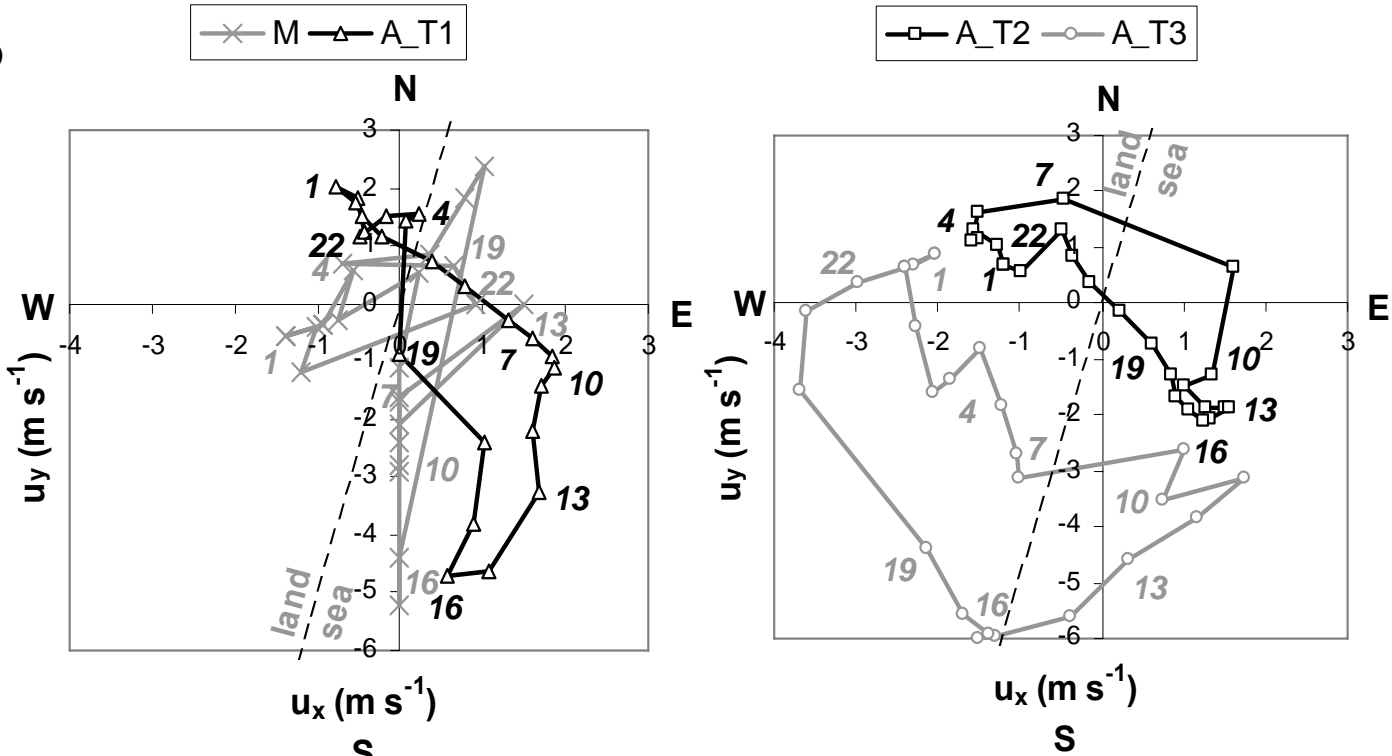

$\mathrm{S}$

(b)

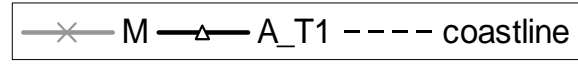

$\longrightarrow$ - A_T2 —-A_T3 -- - coastline

Fig. 10. Surface wind hodographs for Pula-airport (a), Opatija (b), Rijeka (c) and Malinska (d) and the corresponding modeled hodographs on 19 June 2000: measurements (M) and the A_T1 case are on the left, the test without islands (A_T2) and the test with idealized topography that is lower than $10 \mathrm{~m}$ (A_T3) are on the right. The wind vectors are directed toward the origin of the coordinate system. The numbers represent local standard time and the dashed line the orientation of the local coastline. The exception is Pula-airport, which is situated at the tip of Istria peninsula with the nearest coastline being $10 \mathrm{~km}$ away.

easterly wind blowing in the morning and a westerly wind in the afternoon. The modeled wind mimics the measurements with the largest difference seen in the afternoon when a southwesterly wind prevails in the A_T1 case. In the A_T2 test the wind is stronger around the noon and weaker in the afternoon, as compared to the A_T1 case. During the nighttime the A_T2 test shows only small deviations. The largest difference appears between the A_T1 case and the A_T3 one. In the latter the southwesterly winds blow for almost $24 \mathrm{~h}$ over Pula-airport because the convergence zone develops near the eastern part of Istria, far away from the station (Prtenjak et al., 2006).

In Opatija the A_T1 hodograph shows the behavior more regular than the measured one (Fig. 10b). Comparing the morning wind speed in the A_T1 case and the A_T2 one, it is seen that the absence of islands increases the wind speeds. The larger speeds cause stronger advection of the cold marine air that is followed by the lower surface air temperature 

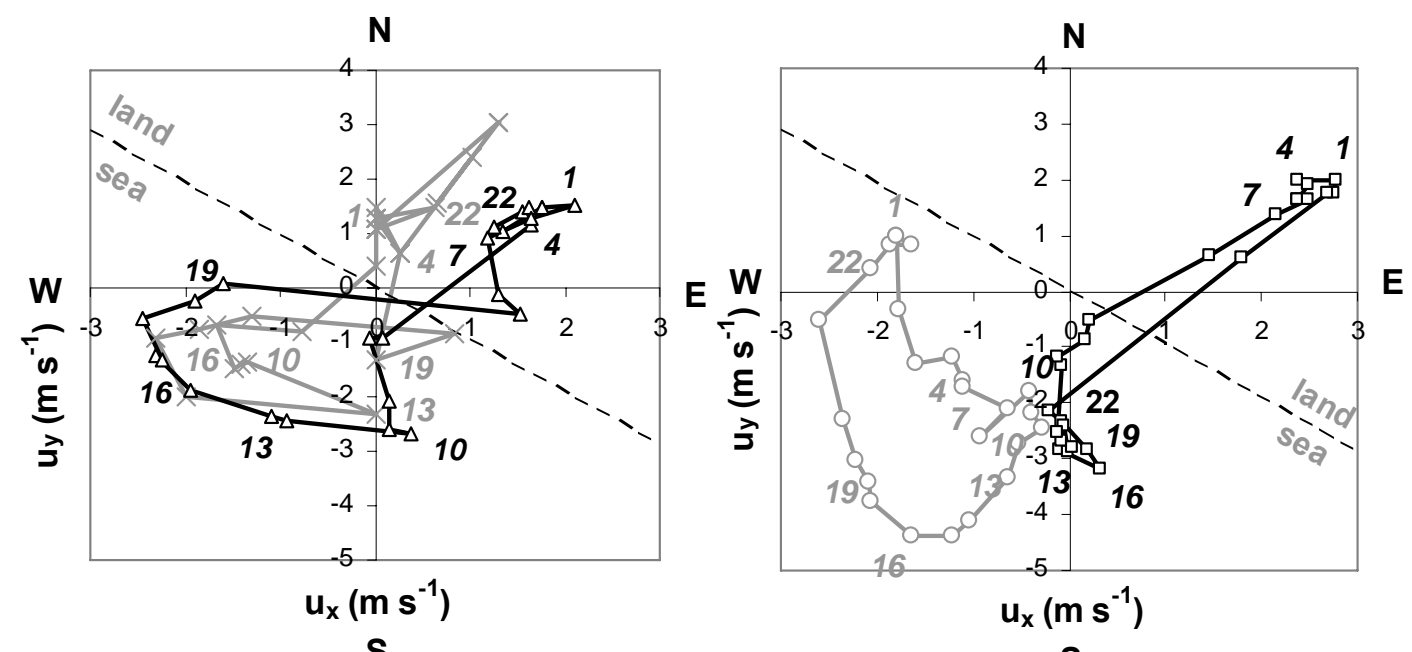

(c)

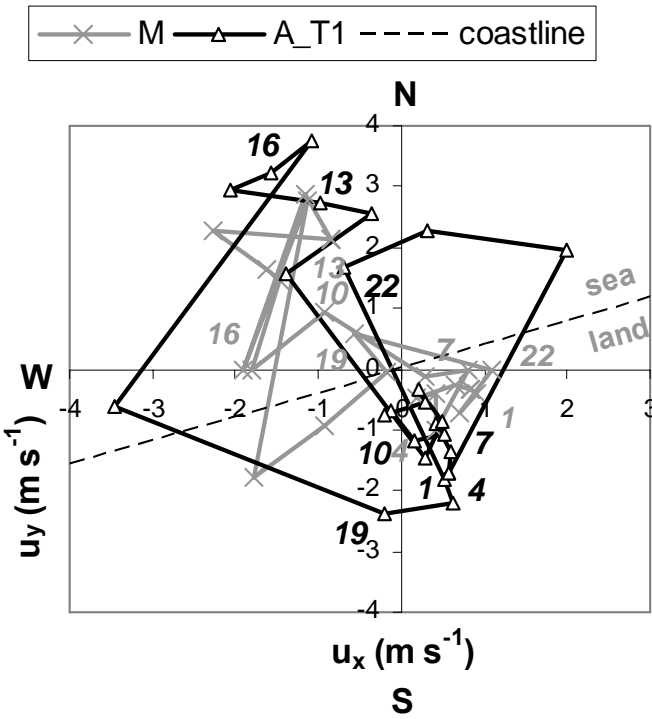

(d)

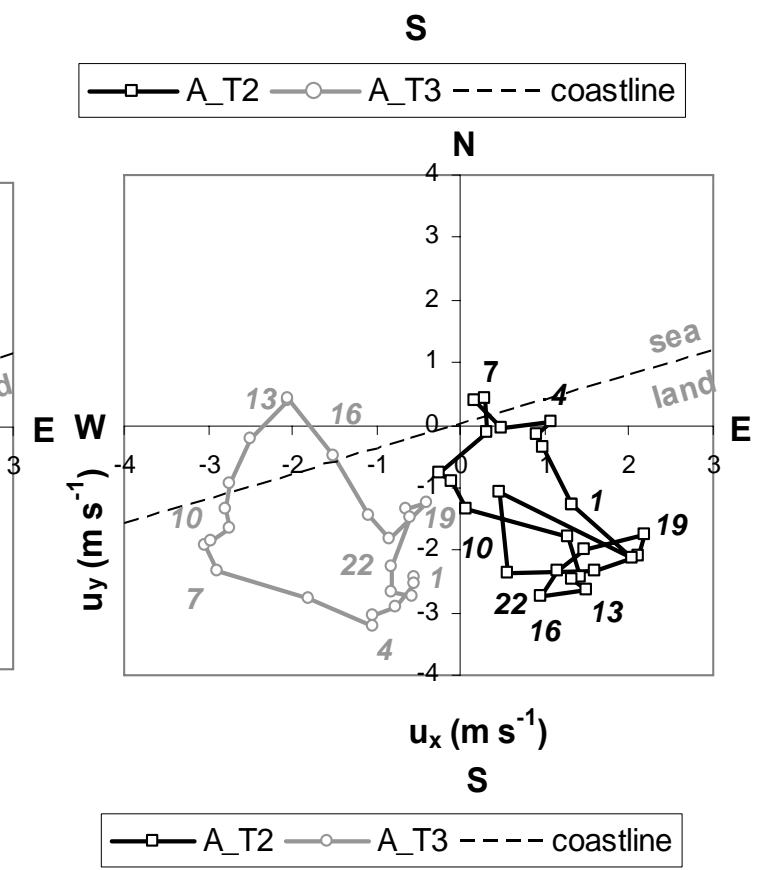

Fig. 10. Continued.

during the day. Due to the smaller land-sea temperature difference the wind speed decreases by $\sim 50 \%$ in the afternoon. Therefore, the length of the ellipse is smaller in the A_T2 test as compared with the A_T1 case (Figs. 6 and 7). An additional reason for the overall low wind speed is the absence of both the canalizing of the air flow and the mesoscale eddies near Opatija within the Rijeka Bay. The largest difference exists between the A_T1 case and the A_T3 test, with a pronounced $\mathrm{CW}$ rotation of the hodograph (Fig. 10b).

In Rijeka, as already observed, both the measured and very similar A_T1 hodographs have the CW rotation (Fig. 10c). The hodograph for the A_T2 test displays significant differences compared to the A_T1 case. In the A_T1 case the daytime mesoscale eddy with the $\mathrm{CW}$ rotation in the surface wind field forms inside the Rijeka Bay (Fig. 2). A superposition between the eddy and the daytime onshore flow creates a more pronounced $\mathrm{CW}$ rotation in the A_T1 wind than in the A_T2 test. As for Opatija, the onshore flow in the A_T2 test has a larger (by 25\%) morning wind speed than in the A_T1 case and smaller afternoon values. By removing the topography in the A_T3 test the southwesterly SB is enhanced by the background wind without a nighttime offshore flow (Fig. 10c).

Malinska is placed in the area where the prevailing ACW rotation of the measured and modeled wind exists (Fig. 10d). This coastal station is influenced by two mesoscale features: the mesoscale eddy inside the Rijeka Bay and the convergence zone above the northeastern part of Krk (Fig. 2). The 
numerical results show that the $\mathrm{ACW}$ rotation of the wind in the A_T1 case is mostly due to the convergence zone, which is generated east of Malinska. Hence, the morning northwesterly winds are shifted eastward during the afternoon. In the A_T2 test, since there are no islands, the hodograph depicts the wind rotation above sea surface: first ACW rotation and afterwards rather stationary wind behavior. Although the geometry of the coast is conserved in the A_T3 test, the very low topography $(\leq 10 \mathrm{~m})$ is unable to generate the convergence zone above the island of Krk. In this case the hodograph shows only the $\mathrm{CW}$ rotation (Fig. 10d).

\section{Conclusions}

A typical atmospheric boundary layer evolution at the northern Croatian coast is addressed here. The diurnal evolution of the wind hodographs in the area has been analyzed during several sea/land breeze intervals. For this purpose a limited set of observations, as well as the results of the three-dimensional nonhydrostatic numerical mesoscale model (MEMO6) are used.

The study is based on the rotary-component method, which has been applied to both observations and the numerical outputs related to four chosen cases. By this method a spatial distribution of the clockwise versus anti-clockwise rotation of the sea/land breezes was obtained. Several areas of the anti-clockwise rotation of diurnal wind exist, such as the pass between the Ćićarija and Risnjak mountains, some NW parts of the islands of Krk and Cres, and the large part of mainland along Velebit Channel. This result is in agreement with the existing knowledge about the prevailing diurnal wind rotation at several stations examined in the area of interest. Furthermore, an application of the rotary-component method on the sensitivity tests showed more specifically which coastal areas, along with the corresponding thermal circulations, are affected by the coastal geometry and terrain.

The finer characteristics of the wind hodographs are explained using the measurements and numerical results. Particular attention is paid to the comparison among hodographs for one day, i.e. 19 June 2000 , for both the chosen simulated interval and the two sensitivity tests. At Pula-airport and Malinska diurnal winds are connected with the convergence zones while Rijeka and Opatija are influenced by the slope winds. These results clarify hodograph shapes at the particular stations and the physical reasons for them. Therefore, the authors believe that the findings will help to design future experiments aimed at an understanding of a coastal phenomena that are deemed important in a densely populated area, such as the one considered here.

Acknowledgements. This work has been supported by the Ministry of Science, Education and Sports (BORA grant No. 119-11930861311, grant No. 119-1193086-3085 and partly from grant No. 0041193086-3065). The authors are indebted to the Meteorological and
Hydrological Service of the Republic of Croatia and the Meteorological Department of the Croatian Air Traffic Control at Zagreb Airport for providing the meteorological data. Comments by anonymous reviewers led to notable improvements of the paper.

Topical Editor S. Gulev thanks C. Lac and another anonymous referee for their help in evaluating this paper.

\section{References}

Alpert, P., Kusuda, M., and Abe, N.: Anticlockwise rotation, eccentricity and tilt angle of the wind hodograph. Part II: An observational study, J. Atmos. Sci., 41, 3568-3583, 1984.

Blackadar, A. K.: The vertical distribution of wind and turbulent exchange in a neutral atmosphere, J. Geophys. Res., 67, 30953102, 1962.

Bubnova, R., Hello, G., Benard, P., and Geleyn, J.-F.: Integration of the fully elastic equations cast in the hydrostatic pressure terrain-following coordinate in the framework of the ARPEGE/ALADIN NWP system, Mon. Weather Rev., 123, 515-535, 1995.

Caballero, R. and Lavagnini, A.: A numerical investigation of the sea breeze and slope flows around Rome, Il Nuovo Cimento, 25, 287-304, 2002.

Deardorf, J. W.: Efficient prediction of ground surface temperature and moisture, with inclusion of a layer of vegetation, J. Geophys. Res., 83, 1889-1903, 1978.

Gonella, J.: A rotary-component method for analyzing meteorological and oceanographic vector time series, Deep-Sea Res., 19, 833-846, 1972.

Grisogono, B., Ström, L., and Tjernström, M.: Small-scale variability in the coastal atmospheric boundary layer, Boundary-Layer Meteorol., 88, 23-46, 1998.

Grisogono, B., Kraljević, L., and Jeričević, A.: The low-level katabatic jet height versus Monin-Obukhov height, Q. J. Roy. Meteorol. Soc., 133, 2133-2136, 2007.

Haurwitz, B.: Comments on the sea-breeze circulation, J. Meteorol., 4, 1-8, 1947.

Heimann, D.: A model-based wind climatology of the eastern Adriatic coast, Meteorol. Z., 10, 5-16, 2001.

Ivatek-Šahdan, S. and Tudor, M.: Use of high-resolution dynamical adaptation in operational suite and research impact studies, Meteorol. Z., 13, 99-108, 2004.

Klaić, Z. B., Nitis, T., Kos, I., and Moussiopoulos, N.: Modification of local winds due to hypothetical urbanization of the Zagreb surroundings, Meteorol. Atmos. Phys., 79, 1-12, 2002.

Kunz, R. and Moussiopoulos, N.: Simulation of the wind field in Athens using refined boundary conditions, Atmos. Environ., 29, 3575-3591, 1995.

Kusuda, M. and Alpert, P.: Anti-clockwise rotation of the wind hodograph. Part I: Theoretical study, J. Atmos. Sci., 40, 487499, 1983.

Kusuda, M. and Abe, N.: The contribution of horizontal advection to the diurnal variation of the wind direction of land-sea breezes: Theory and observations, J. Meteorol. Soc. Japan, 67, 177-184, 1989.

Lukšić, I.: Diurnal winds at Senj, Geofizika, 6, 59-74, 1989 (in Croatian).

Mahrt, L.: The influence of nonstationarity on the turbulent fluxgradient relationship for stable stratification, Bound.-Lay. Mete- 
orol., 125, 245-264, 2007.

Mahrt, L. and Vickers, D.: Extremely weak mixing in stable conditions, Bound.-Lay. Meteorol., 119, 19-39, 2006.

Miller, S. T. K., Keim, B. D., Talbot, R. W., and Mao, H.: Sea breeze: Structure, forecasting, and impacts, Rev. Geophys., 41, 1-31, 2003.

Moussiopoulos, N. (Ed.): The EUMAC zooming model: model structure and applications. Garmisch-Partenkirchen: EUROTRAC Special Publication, ISS, pp 266, 1994.

Nitis, T., Kitsiou, D., Klaić, Z. B., Prtenjak, M. T., and Moussiopoulos, N.: The effects of basic flow and topography on the development of the sea breeze over a complex coastal environment, Q. J. Roy. Meteorol. Soc., 131, 305-328, 2005.

Orlić, M., Penzar, B., and Penzar, I.: Adriatic sea and land breezes: Clockwise versus anticlockwise rotation, J. Appl. Meteorol., 27, 675-679, 1988.

Pandžić, K. and Likso, T.: Eastern Adriatic typical wind field patterns and large-scale atmospheric conditions, Int. J. Climatol., 25, 81-98, 2005.

Prtenjak, M. T.: Main characteristics of sea/land breezes along the eastern coast of the Northern Adriatic, available at: http:// geofizika-journal.gfz.hr/vol20.htm, Geofizika, 20, 75-92, 2003.

Prtenjak, M. T., Grisogono, B., and Nitis, T.: Shallow mesoscale flows at the north-eastern Adriatic coast, Q. J. Roy. Meteorol. Soc., 132, 2191-2216, 2006.
Prtenjak, M. T. and Grisogono, B.: Sea/land breezes climatological characteristics along the northeastern Adriatic coast, Theoret. Appl. Climatol., 90, 201-215, doi:10.1007/s00704-006-0286-9, 2007.

Sandvik, A. D.: Implementation and validation of a condensation scheme in a nonhydrostatic mesoscale model, Mon. Weather Rev., 126, 1882-1905, 1998.

Simpson, J. E.: Sea Breeze and Local Winds. Cambridge University Press, 1994.

Simpson, J. E.: Diurnal changes in sea-breeze direction, J. Appl. Meteorol., 35, 1166-1169, 1996.

Steyn, D. G. and Kallos, G.: A study of the dynamics of hodograph rotation in the sea breezes of Attica, Greece, Bound.-Lay. Meteorol., 58, 215-228, 1992.

Soriano, C., Baldasano, J. M., Buttler, W. T., and Moore, K. R.: Circulatory patterns of air pollutants within the Barcelona air basin in a summertime situation: Lidar and numerical approaches, Bound.-Lay. Meteorol., 98, 33-55, 2001.

Wyngaard, J. C.: Toward numerical modeling in the "Terra Incognita”, J. Atmos. Sci., 61, 1816-1826, 2004. 